\title{
Design and test of a six-rotor unmanned aerial vehicle (UAV) electrostatic spraying system for crop protection
}

\author{
Zhang Yanliang, Lian Qi, Zhang Wei" \\ (College of Engineering, Heilongjiang Bayi Agricultural University, Daqing 163319, Heilongjiang, China)
}

\begin{abstract}
In recent years, multi-rotor unmanned aerial vehicle (UAV) crop protection operations have experienced tremendous growth. Compared with manual operations, they have advantages such as high operational efficiency, small pesticide dosage, and low pesticide hazards for humans. However, the tiny droplets produced during UAV spraying for crop protection are affected by the rotor air flow and will drift in all directions in an uncontrollable manner, severely affecting the pesticide deposition pattern and resulting in pesticide waste. To improve pesticide use efficiency during multi-rotor UAV spraying, an electrostatic spray system was designed based on electrostatic spray technology and a six-rotor UAV. The proper operation parameters for the UAV electrostatic spray were determined by test, which were spray altitude of $50 \mathrm{~cm}$ above the crop, spray pressure of $0.3 \mathrm{MPa}$ and charging voltage of $9 \mathrm{kV}$. Field test was performed based on these parameters. The results showed that compared with non-electrostatic spray, the electrostatic spray improved by $13.6 \%$ in the average deposition density above the sampling device and $32.6 \%$ in the middle. The research can provide a reference for designing multi-rotor UAV electrostatic spray devices.
\end{abstract}

Keywords: unmanned aerial vehicle (UAV), multi-rotor, electrostatic spraying, pesticide use efficiency, plant protection DOI: $10.25165 /$ j.ijabe.20171006.3460

Citation: Zhang Y L, Lian Q, Zhang W. Design and test of a six-rotor unmanned aerial vehicle (UAV) electrostatic spraying system for crop protection. Int J Agric \& Biol Eng, 2017; 10(6): 68-76.

\section{Introduction}

Pests and weeds severely affect crop yield and quality $^{[1]}$. Ground crop protection spray machines are constrained by many factors including topography and later stage of crop growth, and have poor field adaptability and operational results ${ }^{[2]}$. As a result, agricultural aviation has become popular worldwide ${ }^{[3-5]}$. Large agricultural aircraft crop protection operations have the advantages such as fast operation and high efficiency ${ }^{[6]}$. However, because an aircraft flies at high

Received date: 2017-04-29 Accepted date: 2017-10-12

Biographies: Zhang Yanliang, $\mathrm{PhD}$ candidate, Associate Professor, research interests: agricultural aviation application. Email: 15804598777@163.com; Lian Qi, PhD candidate, research interest: agricultural aviation, Email: qqtt912@yeah.net.

*Corresponding author: Zhang Wei, PhD, Professor, research interest: agricultural mechanization engineering. College of Engineering, Heilongjiang Bayi Agricultural University, Daqing 163319, Heilongiiang Province, China. Tel: +86-459-6819212, Email: zhang66wei@126.com. speeds and operates at high altitudes, the vortices at both ends of the wings cause the tiny droplet spray to drift before reaching the ground $^{[7-9]}$, which pollutes the environment and wastes pesticide ${ }^{[10]}$. In comparison, unmanned aerial vehicle (UAV) crop protection operations offer the advantages of a low operational altitude, a controllable flight velocity and better field adaptability, particularly for small fields and diversified crop planting zones ${ }^{[11,12]}$. Therefore, UAV crop protection technology should be studied further.

In recent years, researchers worldwide have conducted numerous studies on how to improve droplet deposition results in UAV operations. Gao et al. ${ }^{[13,14]}$ performed UAV corn borer prevention tests using $10 \%$ chlorpyrifos pesticide, the results showed that when the spray altitude was $2.5 \mathrm{~m}$ and the pesticide spray was $0.42 \mathrm{~L} / \mathrm{mu}\left(1 \mathrm{mu}=0.0667 \mathrm{hm}^{2}\right)$, the optimal prevention effect reached $80.7 \%$, and the pesticide droplet deposition density at the female corn ear reached $15.6 \mathrm{drops} / \mathrm{cm}^{2}$. Qin et al. ${ }^{[15]}$ studied the effect of N-3 UAV operation 
parameters on droplet deposition and distribution at the corn canopy, the results showed that the maximum deposition density of the spray droplets and the optimal deposition uniformity were achieved when the operation altitude was $7 \mathrm{~m}$ and the horizontal spray coverage was $7 \mathrm{~m}$. Carlton et al. ${ }^{[16]}$ studied the effect of the air flow velocity and nozzle diameter on the deposition range of rotor UAV electrostatic spraying, and set up a mathematical model based on the results. To investigate the factors that influence pesticide droplet deposition and the effects of each factor during UAV operation, Qiu et al. $^{[17]}$ created a mathematical model to describe how the deposition density and deposition uniformity are affected by the flight velocity and altitude, and verified the feasibility of the model via field tests. $\mathrm{Hu}$ et al. ${ }^{[18]}$ performed field experiments to study how the flight height, speed and interval influence the environment around tea to determine the proper flight parameters of an unmanned helicopter for frost protection of a tea plantation.

These previous studies mainly focused on the effects of UAV operation parameters on the droplet deposition, and determined the optimal operation parameters for UAV crop protection via testing. However, these studies were based on different models and had different operational goals. As a result, the influencing rules were different, and it is difficult for determining the optimal operation parameters. In order to find a common method for improving droplet deposition, the electrostatic spray technology, which is widely deployed in ground crop protection machines, was considered applying to UAVs to effectively improve the droplet deposition on a target, thus reducing droplet drift $^{[19-21]}$. For instance, He et al. ${ }^{[22]}$ developed an electrostatic spray system for orchards, and field test results showed that charged droplets could prevent $50 \%-70 \%$ of the pesticide waste. In the United States of America, Kirk et al. ${ }^{[23]}$ performed field electrostatic spray tests, the results showed that compared with conventional spray technology, electrostatic spray technology reduced droplet drift by $20 \%-30 \%$. The first electrostatic nozzle for aerial spraying was developed by Calton and Isler ${ }^{[24]}$. The results from aerial spray tests showed that this device could produce well charged droplets.

However, studies on electrostatic spray technology and equipment for multi-rotor UAVs are scarce. $\mathrm{Ru}$ et al. ${ }^{[25]}$ designed an electrostatic spray device based on a cone-shaped spray nozzle and installed it in a UAV for field test, the results showed that the electrostatic spray increased the average droplet coverage at the canopy, middle and bottom of a target plant by 35.4, 26 and 9 droplets $/ \mathrm{cm}^{2}$, respectively. However, the electrostatic spray method cannot effectively suppress droplet drift. The hollow cone nozzle spray has severe drift ${ }^{[26]}$ and is unsuitable for UAV crop protection operations.

In this study, electrostatic spray technology and multi-rotor UAV crop protection operations were combined to develop a fan-shaped electrostatic spray system. Additionally, proper UAV electrostatic spray operation parameters were defined to achieve better droplet deposition and to reduce pesticide dosage.

\section{Multi-rotor UAV and electrostatic spray system design}

Based on the current UAV models, crop protection operation requirements, UAV loading capability and flight duration, under an identical load, a six-rotor UAV is thought more stable than a four-rotor UAV and consumes less energy than an eight-rotor UAV. In this research, a six-rotor UAV with a $10 \mathrm{~L}$ loading capacity was designed using Dajiang flight control system. An electrostatic spray system is created based on this UAV. A three-dimensional (3D) model of the overall structure is constructed using UG software, as shown in Figure 1. The main parameters are listed in Table 1.

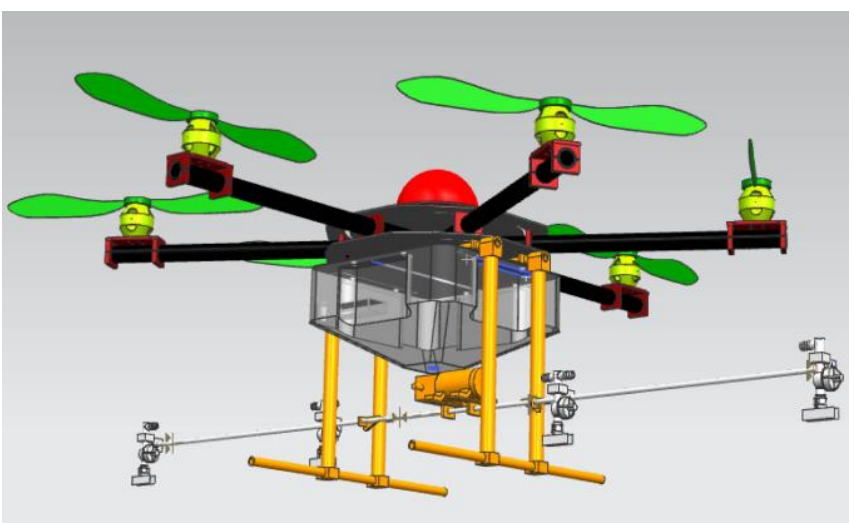

Figure 1 Three-dimensional model of the studied unmanned aerial vehicle (UAV) 
Table 1 Main parameters of the studied unmanned aerial vehicle (UAV)

\begin{tabular}{lc}
\hline \multicolumn{1}{c}{ Parameters } & Numerical value \\
\hline Maximum flight velocity $/ \mathrm{m} \cdot \mathrm{s}^{-1}$ & 16 \\
Maximum load/kg & 10 \\
Number of rotors & 6 \\
Rotor diameter $/ \mathrm{mm}$ & 180 \\
Overall weight $/ \mathrm{kg}$ & 10 \\
Vehicle dimensions $/ \mathrm{mm}^{3}$ & $1500 \times 400 \times 600$ \\
Flight duration $/ \mathrm{min}$ & 25 \\
Water pump power $/ \mathrm{W}$ & 25 \\
Water pump flow rate $/ \mathrm{L} \cdot \mathrm{min}^{-1}$ & 3.15 \\
Number of nozzles & 4 \\
Nozzle mast length $/ \mathrm{m}$ & 1.5 \\
\hline
\end{tabular}

2.1 Electrostatic spray system components and operation principle

The electrostatic spray system consists of a power supply, a diaphragm liquid pump, a spray container, a pipe, a nozzle mast, an electrostatic nozzle and a high voltage electrostatic generator. During operations, the power supply provides electricity to the liquid pump, and the pesticide is pumped from the spray container via the pipe to the electrostatic nozzle in the nozzle mast. The electrostatic nozzles at the two sides of the nozzle mast are connected to the anode and cathode of the electrostatic generator via wires so that positive and negative electrical charges in the pipe and spray container are neutralized to improve system safety. The connections of the system components are shown in Figure 2.

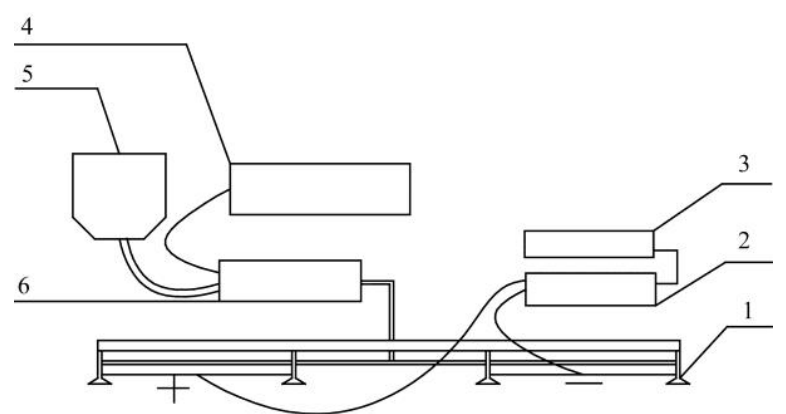

1. Electrostatic nozzle 2. Electrostatic generator 3. Lithium battery 4. Power supply $\quad$ 5. Spray tank 6. Liquid pump

Figure 2 Connections of the electrostatic spray system

\subsection{Electrostatic nozzle selection}

The electrostatic nozzle is a critical component of an electrostatic spray system. The electrostatic nozzle consists of a nozzle and an induction electrode. There are two types of nozzles for crop protection are commonly used in aerial crop protection, the cone-shaped spray nozzle and fan-shaped spray nozzle ${ }^{[27]}$. To investigate which type is a better choice for multi-rotor UAV crop protection operations, the spray performances of the two nozzles were tested and compared. The droplet distribution uniformity was measured with a laser granulometer, as shown in Figure 3. The purpose of this test was to compare the horizontal particle size distribution of the droplets for the two types of spray nozzles. The test results are listed in Table 2.

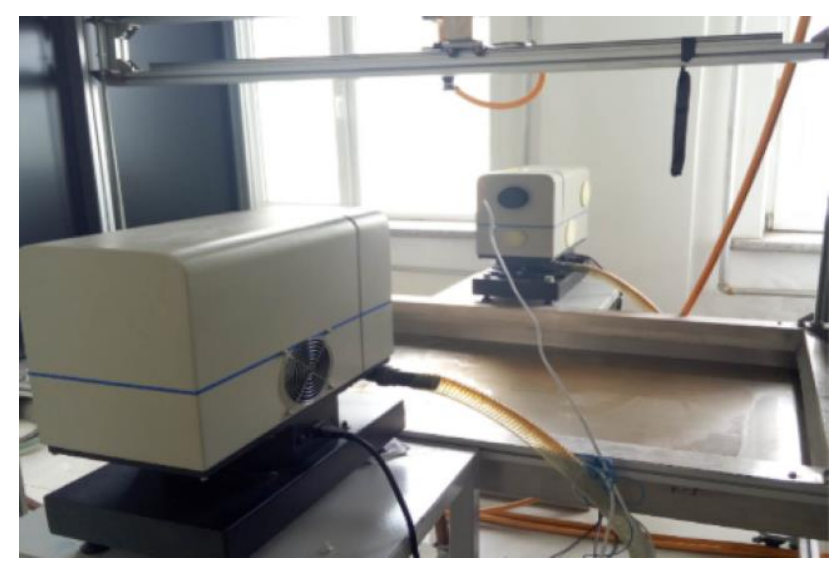

Figure 3 Winner318 laser granulometer

Table 2 Distribution of the droplet size

\begin{tabular}{ccc}
\hline $\begin{array}{c}\text { Test position } \\
/ \mathrm{cm}\end{array}$ & $\begin{array}{c}\text { Cone-shaped particle size } \\
/ \mu \mathrm{m}\end{array}$ & $\begin{array}{c}\text { Fan-shaped particle size } \\
/ \mu \mathrm{m}\end{array}$ \\
\hline-14 & 385.3 & 180.8 \\
-7 & 316.6 & 207.0 \\
0 & 193.7 & 205.5 \\
7 & 286.6 & 182.0 \\
14 & 365.4 & 204.5 \\
Variation coefficient & 0.24 & 0.06 \\
\hline
\end{tabular}

The spray uniformity test was performed in a spray comprehensive test bed, as shown in Figure 4. The purpose of this test was to compare the horizontal spray uniformities for the two types of nozzles with an identical number of nozzles and installation method at different altitudes. The test results are listed in Table 3.

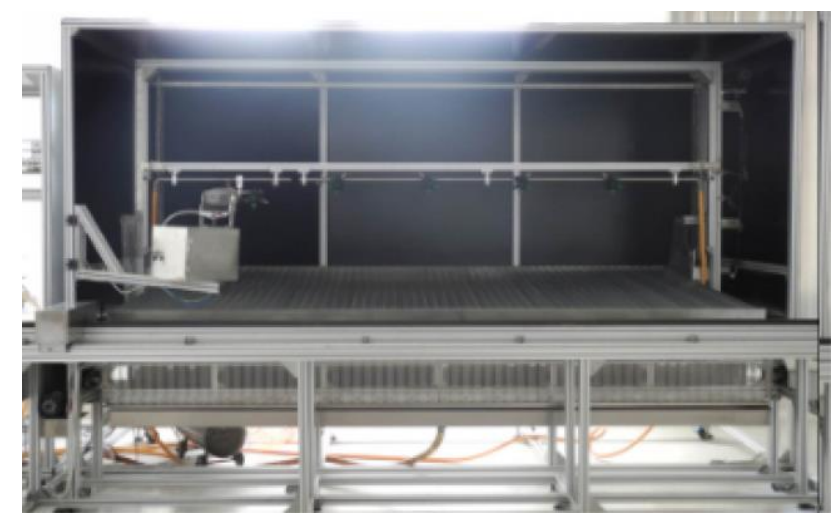

Figure 4 Comprehensive spray test bed 


\section{Table 3 Spray distribution uniformity}

\begin{tabular}{ccc}
\hline Spray altitude/cm & $\begin{array}{c}\text { Fan-shaped variation } \\
\text { coefficient/\% }\end{array}$ & $\begin{array}{c}\text { Cone-shaped variation } \\
\text { coefficient/\% }\end{array}$ \\
\hline 30 & 32.6 & 119.3 \\
40 & 28.3 & 105.2 \\
50 & 24.0 & 94.8 \\
60 & 26.7 & 90.5 \\
70 & 39.8 & 85.7 \\
80 & 40.5 & 79.0 \\
\hline
\end{tabular}

The drift of the droplet from the nozzle due to lateral wind was tested in a wind tunnel test bed, as shown in Figure 5. The purpose of this test was to compare the droplet drifts of the two spray shapes for different lateral wind velocities. The test results are listed in Table 4.

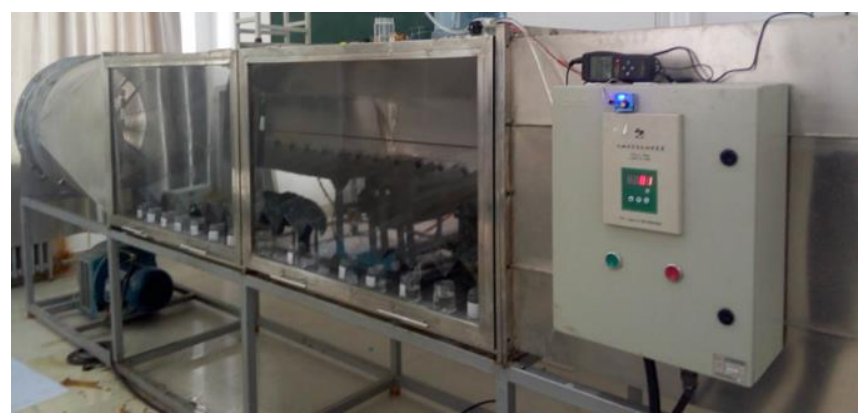

Figure 5 Wind tunnel test rig

Table 4 Drift distance of the droplets

\begin{tabular}{ccc}
\hline Wind velocity $/ \mathrm{m} \cdot \mathrm{s}^{-1}$ & Cone-shaped spray drift/cm & Fan-shaped spray drift/cm \\
\hline 0.4 & 142 & 72 \\
0.5 & 156 & 86 \\
0.6 & 170 & 100 \\
0.7 & 184 & 114 \\
0.8 & 198 & 128 \\
0.9 & 212 & 142 \\
1.0 & 226 & 156
\end{tabular}

The test results show that the particle sizes of the droplets from the fan-shaped spray nozzle are more even in the horizontal direction. When the test altitude is $30-80 \mathrm{~cm}$, the spray distribution of the fan-shaped spray nozzle has better uniformity. In comparison, the spray uniformity variation coefficient of the cone-shaped nozzle decreases as the spray altitude increases. This comparison shows that the cone-shaped nozzle may produce a more even spray distribution at higher altitudes. The wind tunnel drift test results show that the fan-shaped spray at each wind velocity has a shorter drift distance than the cone-shaped spray. The results show that the fan-shaped spray has better wind resistance than the cone-shaped spray. The test results show that compared with the cone-shaped spray nozzle, the fan-shaped spray nozzle is more suitable for multi-rotor UAV low altitude crop protection operations. Therefore, the electrostatic nozzle in this system is based on the fan-shaped electrostatic spray nozzle.

\subsection{Electrode structure design}

The spray shape of the fan-shaped nozzle is scattered, which results in a flat fan-shaped liquid spray. Based on electrostatic induction theory, two electrode plates of the same polarity are designed and installed in parallel on both sides of the spray membrane fan surface to provide electrostatic induction for the spray membrane. The electrode plates are semi-trapezoidal metal sheets embedded in parallel troughs on both sides of the insulation electrode base interior. At the top of the electrode base, there is an opening that has the exact same shape and size as the nozzle. This opening is fastened by elastic deformation of the plastic nozzle and plastic rectangular hole piece. Because the connecting piece does not bear a load, the connection design is simple and reliable. The structural design of the electrode base is shown in Figure 6. Both sides of the electrode base have small circular openings to facilitate a connection between the electrostatic generator wire and electrode. The overall structure is shown in Figure 7. The advantage of this structure is that the material is insulated and provides excellent encapsulation for the electrode, which reduces the adsorption deposition of charged droplets on the external surface of the electrode. At the same time, it effectively prevents air flow from interfering with the spray in the charged area. The electrode base is made of $3 \mathrm{D}$ printed PVC material, which can be quickly produced at a low cost. The weight of the connecting piece is only $10 \mathrm{~g}$, which satisfies the lightweight requirement for key UAV components.

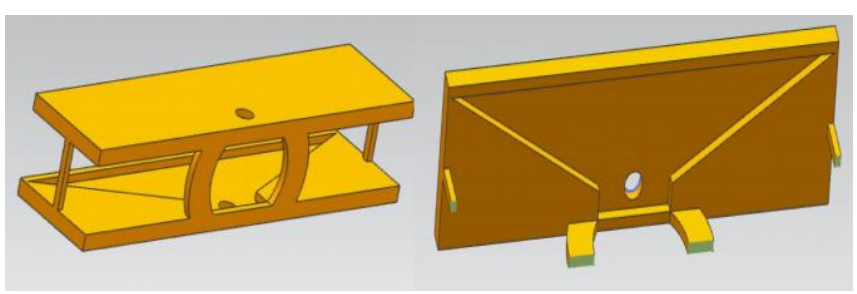

Figure 6 3D drawings of electrode 


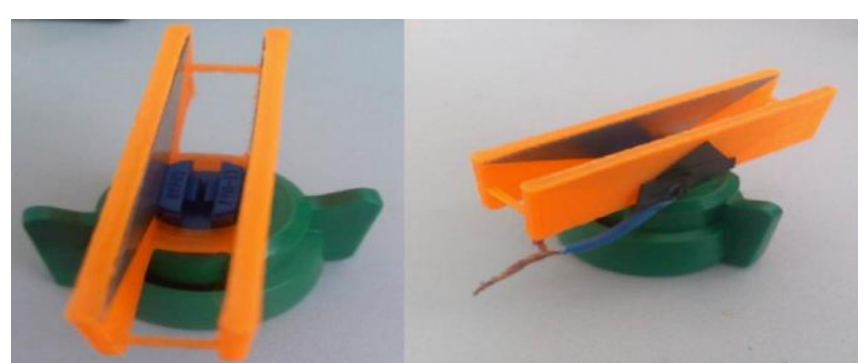

Figure 7 Overall structure of electrostatic sprayer

The spray charging process using the induction electrode is as follows: air is used as an insulation medium, the charging electrode is treated as the high voltage electrode plate of a capacitor, and the unbroken liquid membrane at the nozzle outlet is treated as the grounding electrode plate of a capacitor ${ }^{[13]}$. Therefore, the induction charge on the spray surface is calculated using the formula for the charge quantity of a parallel plate capacitor:

$$
Q=C \times U
$$

where, $Q$ is the charge quantity at the two electrode plates of the capacitor (C), i.e., the charge quantity carried by the liquid membrane; $C$ is the capacitance of the capacitor electrode plate, $\mathrm{F}$; and $U$ is the charging voltage, $\mathrm{V}$. The formula for capacitance $C$ is as follows:

$$
C=\frac{\varepsilon S}{4 \pi k d}
$$

where, $\varepsilon$ is the air dielectric constant; $S$ is the overlap area of the electrode and liquid membrane; $k$ is the electrostatic constant; and $d$ is the distance between the electrode and liquid membrane. Equations (1) and (2) show that major influencing factors of the droplet charge quantity include the charging voltage $U$, the charging electrode overlap area $S$ and the space between the electrode and spray membrane $d$.

The area of the trapezoidal electrode is determined by the electrode height and the lengths of the upper and lower sides of the electrode. The upper side length of the electrode is equal to the nozzle width, which is $20 \mathrm{~mm}$. The angles of the two electrode hypotenuses are set to $110^{\circ}$, which is the same as the spray angle of the fan-shaped nozzle. A highly photosensitive camera is employed to capture images during spraying. Measurement shows that the spray membrane area is from the nozzle to $10 \mathrm{~mm}$ beneath it in the vertical direction. Therefore, the electrode height is set to $10 \mathrm{~mm}$.
It can be seen from Equation (2), when the electrode overlap area is fixed, to improve the electrode charging capacity, the space between the spray electrodes should be reduced. At the same time, to improve system safety, when the space between the spray electrodes is reduced, the droplets should not be sprayed on the interior wall of the electrode. The test results reinforced the idea that no droplets were deposited on the interior wall of the electrode plate. The minimum space between the electrode plates was $8 \mathrm{~mm}$.

\subsection{Determination of electrostatic spray system parameters}

The charging voltage is an important influencing factor of the droplet charging result. The spray pressure and spray altitude directly impact the nozzle spray amount, droplet shape and deposition time. Therefore, these three factors determine the spray result of the crop protection UAV. In this research, the deposition density is used as an operational index to perform an orthogonal test for the three influencing factors. The test factor levels are listed in Table 5. A ball with water sensitive paper is placed under the nozzle to collect charged droplets. The droplet deposition density is measured using a scanner and image analysis software. Based on the orthogonal test table, 9 tests are performed, and the test results are listed in Table 6.

Table 5 Factors of the orthogonal test levels

\begin{tabular}{cccc}
\hline Test level & $\begin{array}{c}\text { Charging voltage } \\
\text { U/kV }\end{array}$ & $\begin{array}{c}\text { Spray pressure } \\
\text { P/MPa }\end{array}$ & $\begin{array}{c}\text { Spray altitude } \\
\text { H/cm }\end{array}$ \\
\hline 1 & 8 & 0.2 & 40 \\
2 & 9 & 0.25 & 50 \\
3 & 10 & 0.3 & 60 \\
\hline
\end{tabular}

Table 6 Orthogonal test results

\begin{tabular}{ccccc}
\hline Test & $\begin{array}{c}\text { Charging } \\
\text { voltage } U / \mathrm{kV}\end{array}$ & $\begin{array}{c}\text { Spray pressure } \\
P / \mathrm{MPa}\end{array}$ & $\begin{array}{c}\text { Spray altitude } \\
H / \mathrm{cm}\end{array}$ & $\begin{array}{c}\text { DepositionDensity/ } \\
\text { drop· } \mathrm{cm}^{-2}\end{array}$ \\
\hline 1 & 1 & 1 & 1 & 142.6 \\
2 & 1 & 2 & 2 & 169.2 \\
3 & 1 & 3 & 3 & 195.7 \\
4 & 2 & 1 & 2 & 145.8 \\
5 & 2 & 2 & 3 & 170.5 \\
6 & 2 & 3 & 1 & 206.6 \\
7 & 3 & 1 & 3 & 141.4 \\
8 & 3 & 2 & 1 & 168.1 \\
9 & 3 & 3 & 2 & 205.7 \\
\hline
\end{tabular}

The droplet deposition density range analysis results are listed in Table 7 . In Table $7, \mathrm{~K} 1, \mathrm{~K} 2$ and $\mathrm{K} 3$ 
represent the standard deviations for the factors (i.e., charging voltage $U$, spray pressure $P$ and spray altitude $H$ ) in the corresponding tests (Levels 1, 2 and 3), and k1, k2 and $\mathrm{k} 3$ are the averages for each level. In the table, the range $R$ is the difference between the maximum and minimum values in the same column, which reflects the impact of the change in each factor level on the test result. A larger range indicates a more significant impact. Table 7 shows that factor $\mathrm{P}$ has the largest range among the 3 factors. Therefore, the spray pressure variation has the most significant impact on the spray deposition density, followed by the charging voltage and then the spray altitude. The optimal design for the electrostatic spray is as follows: the charging voltage $U$ is $9 \mathrm{kV}$, the spray pressure $P$ is $0.3 \mathrm{MPa}$ and the spray altitude $H$ is $50 \mathrm{~cm}$.

Table 7 Droplet deposition density range analysis

\begin{tabular}{cccc}
\hline & $\begin{array}{c}\text { Charging voltage } U \\
\text { /kV }\end{array}$ & $\begin{array}{c}\text { Spray pressure } P \\
/ \mathrm{MPa}\end{array}$ & $\begin{array}{c}\text { Spray altitude } H \\
/ \mathrm{cm}\end{array}$ \\
\hline K1 & 507.5 & 429.8 & 517.3 \\
K2 & 522.9 & 507.8 & 520.7 \\
K3 & 515.2 & 608.0 & 507.6 \\
k1 & 169.17 & 143.27 & 172.43 \\
k2 & 174.30 & 169.27 & 173.57 \\
k3 & 171.73 & 202.67 & 169.20 \\
Range $R$ & 5.13 & 59.40 & 4.37 \\
Optimal level & $\mathrm{U} 2$ & $\mathrm{P} 3$ & $\mathrm{H} 2$ \\
Sequence & & $P>U>H$ & \\
\hline
\end{tabular}

\section{Field test of electrostatic spray}

To better understand how electrostatic droplets deposit on a target when a UAV operates in an outdoor environment, a device was designed to facilitate collection of the charged droplets in an outdoor environment. This device consists of a hollow metal ball and an extendable bar. The metal ball is used to simulate a semi-conductive crop. The spherical structure facilitates droplet collection at different positions to simulate droplet deposition on plant leaves at different angles. It also provides intuitive ways to compare charged droplet deposition changes at different positions. The extendable bar allows for different heights in the field tests to simulate crop heights at different growth stages and also makes the device convenient to carry. The droplet collection device is shown in Figure 8.

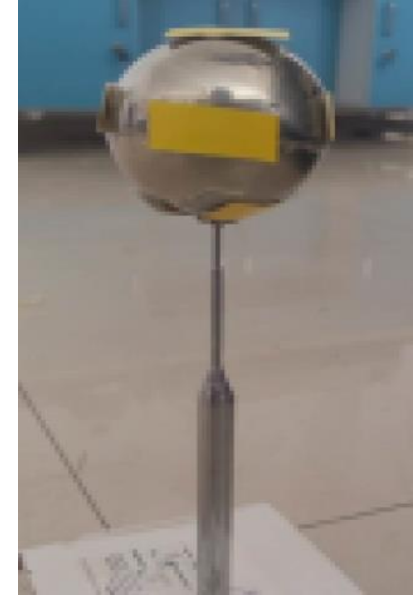

Figure 8 Charged droplet collection device

\subsection{Test method}

To prevent the droplet lateral drift from impacting the test results, the UAV flight directions in the two tests are designed against the wind. The UAV takes off at a location $20 \mathrm{~m}$ from the droplet collection area. When the operational altitude stabilizes at $1.5 \mathrm{~m}$, the UAV proceeds to the droplet collection area. The spray system starts spraying as soon as unmanned flight begins. At $20 \mathrm{~m}$ past the test area, the unmanned helicopter decelerates and descends, and the spray system stops spraying.

(1) Aerial electrostatic spray coverage test

Nine droplet collection points are deployed evenly in $5 \mathrm{~m}$ increments perpendicular to the flight direction. The space between the collection points is $62.5 \mathrm{~cm}$, and the collection point deployment is shown in Figure 9. Five flight tests are performed for electrostatic and non-electrostatic conditions. When the droplet deposition density on the water sensitive paper exceeds 100 drops $/ \mathrm{cm}^{2}$, effective deposition is considered to be achieved. The total distance of all effective deposition collection points after each test is measured using a meter ruler and defined as the effective spray coverage.

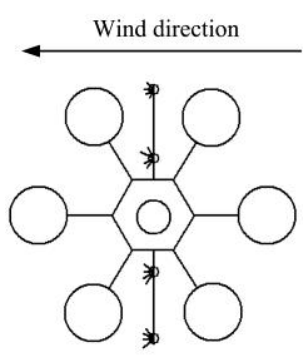

Flight direction

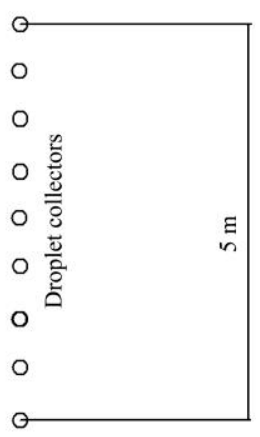

Figure 9 Spray measurement 
(2) Aerial electrostatic spray droplet deposition test

The measured effective spray coverage is used as the width. Nine droplet collection devices $(3 \times 3)$ are evenly distributed in a $10 \mathrm{~m} \times 5 \mathrm{~m}$ rectangular area. Water sensitive paper cards are deployed at the top, middle and bottom of each sampling device to measure the droplet deposition at each part of the electrostatic and non-electrostatic sprays. The placement of the water sensitive paper is shown in Figure 10. In each test, the UAV flies to the sampling area against the wind. The test plan is shown in Figure 11. At the end of the test, the water sensitive paper cards on the sampling devices are collected. The droplet deposition images on the surfaces are scanned using a scanner and analyzed using image analysis software to obtain the droplet deposition data.

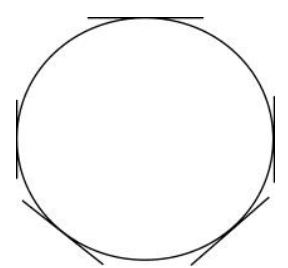

Figure 10 Positions of the water sensitive paper

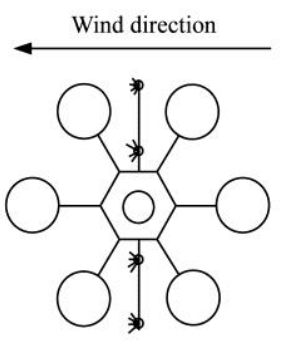

Flight direction

Figure 11 Test scheme of the droplet deposition

\subsection{Test results and analysis}

The droplet deposition distribution obtained at each point for the two spray methods is shown in Figure 12. The test results show that there are 5 effective deposition sampling points, i.e., points 3, 4, 5, 6, and 7. The amount of deposited droplets at all these points exceeded 700 drops, and the quantities at other sampling points are less than 300 drops. Therefore, the effective spray coverage is $2.5 \mathrm{~m}$. The amount of electrostatic spray deposited droplets at the effective sampling points exceeds the amount of non-electrostatic spray deposited droplets. At the border of the effective spray coverage area, the electrostatic spray shows fewer deposited droplets at the sampling points than the non-electrostatic spray. Thus, the charged droplets had a more concentrated deposition area.

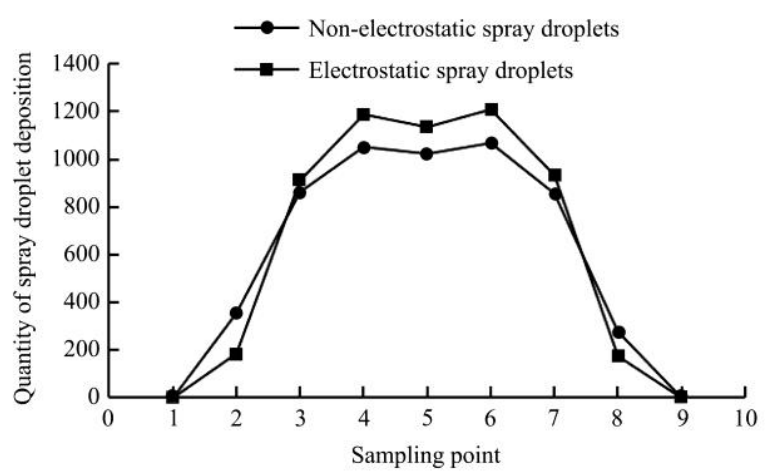

Figure 12 Droplet deposition distribution at each sampling point

The droplet deposition density test results are shown in Figure 13. The test results show that the average electrostatic spray droplet deposition density at the top is $16.1 \mathrm{drops} / \mathrm{cm}^{2}$ more than the non-electrostatic spray density for all nine sampling devices, showing an improvement of $13.6 \%$. The average deposition density in the middle shows an increase of $28 \mathrm{drops} / \mathrm{cm}^{2}$, which is an improvement of $32.6 \%$. Therefore, the electrostatic spray system designed in this study effectively improves the droplet deposition of multi-rotor UAV crop protection operations. Specifically, the deposition of droplets on hidden parts of the target is improved significantly, and pesticide utilization is therefore more efficient.

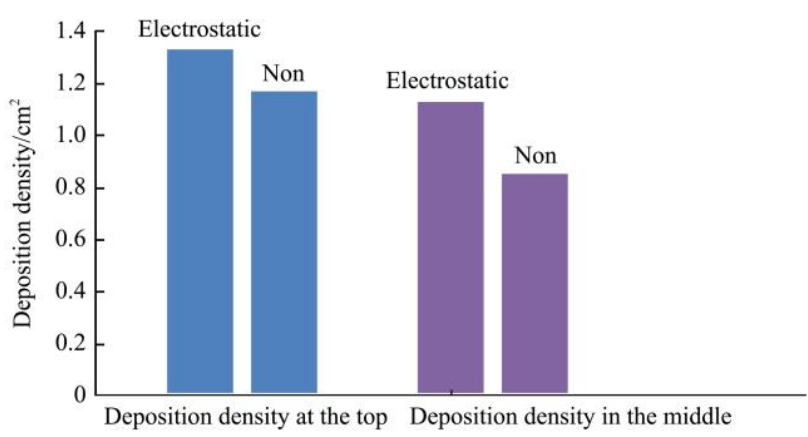

Figure 13 Electrostatic and non-electrostatic spray deposition densities

The test results show that compared with the current cone-shaped electrostatic nozzle used in China ${ }^{[19]}$, the fan-shaped electrostatic nozzle has better spray deposition convergence, more concentrated spray droplet deposition and a smaller drift. Additionally, the fan-shaped electrostatic nozzle shows improved droplet deposition uniformity and penetration capability. Therefore, the fan-shaped electrostatic nozzle is more suitable for UAV 
electrostatic crop protection spray operations.

Although electrostatic spray technology has good performance with ground machines, the working conditions (speed, height) and structure of electrostatic nozzles differ from those of a UVA, resulting in different droplet charging abilities. Therefore, comparing the effects of this technology used with a ground machine with those used with a UAV will be interesting and valuable.

\section{Conclusions and outlook}

In this study, a six-rotor UAV-based fan-shaped induction electrostatic spray system was developed, and the corresponding operational parameters were defined. Field test results show that the effective spray coverage of this UAV is $2.5 \mathrm{~m}$. Compared to non-electrostatic spray, electrostatic spray has a more concentrated droplet deposition and a smaller drift. The average droplet deposition density at the top of the sampling device for electrostatic spray is $16.1 \mathrm{drops} / \mathrm{cm}^{2}$ more than that for non-electrostatic spray, and the deposition density in the middle is $28 \mathrm{drops} / \mathrm{cm}^{2}$ more than that for the non-electrostatic spray. Therefore, the electrostatic spray had a significant improvement on droplet deposition and preventing drift.

However, in this study, the deposition of charged droplets at the bottom of the droplet sampling device was undesirable. Therefore, the electrostatic adsorption force of the charged droplet was not strong enough to overcome its own gravity and generate cyclone adsorption. Therefore, the next step is to investigate how to improve the spray droplet charge-to-mass ratio and the relation between the electrostatic forces of droplets with different charge-to-mass ratios and droplet deposition results.

\section{Acknowledgements}

The authors acknowledge that the research was financially supported by National Key Technology Research and Development Program of the Ministry of Science and Technology of China (2014BAD06B01); Laboratory of Agricultural Mechanization Engineering Project (Provincial Key Laboratory).

\section{[References]}

[1] Berk P, Hocevar M, Stajnko D, Belsak A. Development of alternative plant protection product application techniques in orchards, based on measurement sensing systems: A review. Computers and Electronics in Agriculture, 2016; 124: 273-288

[2] Yang X J, Yan H R, Xu S Z. Current situation and development trend of equipment for crop protection. Transactions of the CSAM, 2002; 33(6): 130-137. (in Chinese)

[3] Lan Y B, Chen S D, Fritz B K. Current status and future trends of precision agricultural aviation technologies. Int $\mathrm{J}$ Agric \& Biol Eng, 2017; 10(3): 1-17.

[4] He X K, Bonds J, Herbst A, Langenakens J. Recent development of unmanned aerial vehicle for plant protection in East Asia. Int J Agric \& Biol Eng, 2017; 10(3): 18-30.

[5] Liu Y F, Noguchi N, Ali R F. Simulation and test of an agricultural unmanned airboat maneuverability model. Int $\mathbf{J}$ Agric \& Biol Eng, 2017; 10(1): 88-96.

[6] Xue X Y, Lan Y B. Agricultural aviation applications in USA. Transactions of the CSAM, 2013; 44(5): 194-201. (in Chinese)

[7] Salyani M, Cromwell R P. Spray drift from ground and aerial applications. Transactions of the ASABE, 1992; 35(4): 1113-1120.

[8] Nuyttens D, de Schampheleire M, Baetens K, Sonck B. The influence of operator-controlled variables on spray drift from field crop sprayers. Transactions of the ASABE, 2007; 50(4): 1129-1140.

[9] Otto S, Loddo D, Baldoin C, Zanin G. Spray drift reduction techniques for vineyards in fragmented landscapes. Journal of Environmental Management, 2015; 162(2): 290-298.

[10] Gil E, Balsari P, Gallart M, Llorensc J, Marucco P, Andersen $\mathrm{P}$ G, et al. Determination of drift potential of different flat fan nozzles on a boom sprayer using a test bench. Crop Protection, 2014; 56(2): 58-68.

[11] Li J Y, Lan Y B, Zhou Z Y, Zeng S, Huang C, Yao W X, et al. Design and test of operation parameters for rice air broadcasting by unmanned aerial vehicle. Int $\mathbf{J}$ Agric \& Biol Eng, 2016; 9(5): 24-32.

[12] Bae Y, Koo Y M. Flight attitudes and spray patterns of a roll-balanced agricultural unmanned helicopter. Applied Engineering in Agriculture, 2013; 29(5): 675-682.

[13] Gao Y Y, Zhang Y T, Zhao Y C. Primary studies on spray driplet distribution and control effects of aerial spraying using unmanned vehicle (UAV) against the corn borer. Plant Protection, 2013; 39(2): 152-157. (in Chinese)

[14] Gao Y Y. Study on distribution of pesticide droplets in gramineous crop canopy and control effect sprayed by unmanned aerial vehicle (UAV). Harbin: Northeast 
Agricultural University, 2013. (in Chinese)

[15] Qin W C, Xue X Y, Zhou L X. Effects of spraying parameters of unmanned aerial vehicle on droplets deposition distribution of maize canopies. Transactions of the CSAE, 2014; 30(5): 50-56. (in Chinese)

[16] Carlton J B. Technique to reduce chemical usage and concomitant drift from aerial sprays: US Patent. 1999.

[17] Hu Y G, Liu S Z, Wu W Y, Wang J Z, Shen J W. Optimal flight parameters of unmanned helicopter for tea plantation frost protection. Int J Agric \& Biol Eng, 2015; 8(5): 50-57.

[18] Zhang W, Hou Y R, Liu X, Lian Q, Fu X M, Zhang B, et al. Wind tunnel experimental study on droplet drift reduction by a conical electrostatic nozzle for pesticide spraying. Int $\mathbf{J}$ Agric \& Biol Eng, 2017; 10(3): 87-94.

[19] Qiu B J, Wang L W, Cai D L, Wu J H. Effects of flight altitude and speed of unmanned helicopter on spray deposition uniform. Transactions of the CSAE, 2013; 29(24): 25-32. (in Chinese)

[20] Hewitt A J, Maber J, Praat J P. Drift management using modeling and GIS systems. Proceedings of the World Congress of Computers in Agriculture and Natural Resources, 2002; pp.290-296.

[21] Teske M E, Thistle H W. Aerial application model extension into the far field. ASAE Annual Meeting, 2003; Paper No. 034019.

[22] He X K, Zeng A J, Liu Y J, Song J L. Precision orchard sprayer based on automatically infrared target detecting and electrostatic spraying techniques. Int J Agric \& Biol Eng, 2011; 4(1): 35-40.

[23] Kirk I W, Hoffmann W C, Carlton J B. Aerial electrostatic spray system performance. Transactions of the ASAE, 2001; 44(5): 1089-1092.

[24] Carlton J B, Isler D A. Development of a device to charge aerial sprays electrostatically. Agricultural Aviation, 1966; 8(2): 44-51.

[25] Ru Y, Jin L, Jia Z C, Bao R, Qian X D. Design and experiment on electrostatic spraying system for unmanned aerial vehicle. Transactions of the CSAE, 2015; 31(8): 42-47. (in Chinese)

[26] Liu Q, Qi L J, Fu Z T, Wang J, Cooper S E. Experimental research on droplet travel time and deposition characteristic from sprayer. Transactions of the CSAM, 2007; 38(6): 62-65. (in Chinese)

[27] Jiang Y, Chen C, Li H, Xiang Q J. Influences of nozzle parameters and low-pressure on jet breakup and droplet characteristics. Int J Agric \& Biol Eng, 2016; 9(4): 22-32. 